\title{
Childhood IQ and risk of bipolar disorder in adulthood: prospective birth cohort study
}

\author{
Daniel J. Smith, Jana Anderson, Stanley Zammit, Thomas D. Meyer, Jill P. Pell and Daniel Mackay
}

\section{Background}

Intellectual ability may be an endophenotypic marker for bipolar disorder.

\section{Aims \\ Within a large birth cohort, we aimed to assess whether childhood IQ (including both verbal IQ (VIQ) and performance IQ (PIQ) subscales) was predictive of lifetime features of bipolar disorder assessed in young adulthood.}

\section{Method}

We used data from the Avon Longitudinal Study of Parents and Children (ALSPAC), a large UK birth cohort, to test for an association between measures of childhood IQ at age 8 years and lifetime manic features assessed at age 22-23 years using the Hypomania Checklist-32 (HCL-32; $n=1881$ individuals). An ordinary least squares linear regression model was used, with normal childhood IQ (range 90-109) as the referent group. We adjusted analyses for confounding factors, including gender, ethnicity, handedness, maternal social class at recruitment, maternal age, maternal history of depression and maternal education.

\section{Results}

There was a positive association between IQ at age 8 years and lifetime manic features at age 22-23 years (Pearson's correlation coefficient 0.159 (95\% Cl 0.120-0.198), P>0.001).
Individuals in the lowest decile of manic features had a mean full-scale IQ (FSIQ) which was almost 10 points lower than those in the highest decile of manic features: mean FSIQ $100.71(95 \% \mathrm{Cl}$ 98.74-102.6) v. 110.14 (95\% Cl 107.79-112.50), $P>0.001$. The association between IQ and manic features was present for FSIQ, VIQ and for PIQ but was strongest for VIQ.

\section{Conclusions}

A higher childhood IQ score, and high VIQ in particular, may represent a marker of risk for the later development of bipolar disorder. This finding has implications for understanding of how liability to bipolar disorder may have been selected through generations. It will also inform future genetic studies at the interface of intelligence, creativity and bipolar disorder and is relevant to the developmental trajectory of bipolar disorder. It may also improve approaches to earlier detection and treatment of bipolar disorder in adolescents and young adults.

\section{Declaration of interest}

None.

\section{Copyright and usage}

(c) The Royal College of Psychiatrists 2015. This is an open access article distributed under the terms of the Creative Commons Non-Commercial, No Derivatives (CC BY-NC-ND) licence.
The possibility of a link between bipolar disorder and positive attributes such as intelligence, productivity, sociability and creativity has been discussed since antiquity ${ }^{1}$ and has been the subject of a number of contemporary reports. ${ }^{2-5}$ Biographical studies may suggest a relationship between bipolar disorder and exceptional intellectual and/or creative ability but are to some extent limited by non-systematic diagnoses and the potential for recall and selection biases. ${ }^{6-9}$

More recently, Swedish population registries have identified that, compared with the general population, individuals with bipolar disorder, as well as their healthy siblings, are more likely to be employed in the creative professions ${ }^{10}$ and that traits associated with bipolar disorder may be linked to leadership qualities. ${ }^{11}$ Higier and colleagues ${ }^{12}$ assessed a large population sample of probands with bipolar disorder - along with their discordant (non-bipolar) co-twins and controls - on measures of temperament and cognitive function. Relative to controls, bipolar co-twins had elevated scores on 'positive temperament' and superior performance on tests of verbal learning and fluency, raising the possibility that sociability and verbal proficiency might represent adaptive endophenotypic traits which have contributed to the persistence of bipolar disorder across generations. ${ }^{12}$

Another line of evidence about a potential link between intellectual ability and risk of bipolar disorder comes from the Dunedin birth cohort, which found that lower childhood IQ was associated with later development of several psychiatric disorders, including schizophrenia spectrum disorder, depression and anxiety disorder, but that higher childhood IQ was associated with mania in adulthood. ${ }^{13}$ The authors of this study were cautious about this finding because only eight individuals developed mania, but they suggested a need for replication in other large-scale prospective cohorts.

MacCabe and colleagues ${ }^{14}$ investigated this further by linking Swedish educational and hospital admissions data to test the association between scholastic achievement at age 16 years and subsequent risk of schizophrenia and bipolar disorder. They found that, as expected, poor scholastic achievement was associated with schizophrenia in males and females but that male students with excellent school performance (relative to students with average grades), as well as those with very poor performance, had an increased risk of admission for bipolar disorder. ${ }^{14}$ Although Zammit and colleagues ${ }^{15}$ did not find an association between IQ at age 18 years and subsequent risk of bipolar disorder within the 1969 Swedish conscription cohort $(n=50087)$, a more recent and much larger cohort of Swedish military conscripts ( $n=1049607$ ), assessed between the years 1969 and 1994, has identified high IQ as a possible risk factor for bipolar disorder in men, albeit only for the minority who had a 'pure' (non-comorbid) form of the disorder. ${ }^{16}$ It is notable that this latter study also found that men with the highest scores on verbal or technical abilities (in contrast to spatial and logical ability) were at highest risk of non-comorbid bipolar disorder. ${ }^{16}$

All of the studies above involved samples where index patients were identified as having a clinical diagnosis of bipolar disorder. In the present study, we take a dimensional approach by assessing the relationship between childhood IQ scores at age 8 years (including both verbal IQ (VIQ) and performance IQ (PIQ) 
subgroups) and the subsequent development of lifetime manic features (assessed at age 22 years) within a large UK birth cohort while taking account of a range of potential confounding factors. To our knowledge, a dimensional approach has not been used in previous studies but has the advantage that (as a continuous measure) it is statistically more powerful and, further, does not make any assumptions about the correct threshold score for defining lifetime hypomania. We have also used a score derived from those 28 items within the Hypomania Checklist-32 (HCL-32) ${ }^{17}$ which we previously identified as constituting a linear score. ${ }^{18}$ Given the convergence of evidence summarised above, we hypothesised that high IQ in general, and high VIQ in particular, may be markers for the later development of manic features in young adulthood.

\section{Method}

This study received ethical approval from the Avon Longitudinal Study of Parents and Children (ALSPAC) Law and Ethics Committee and local research ethics committees. All participants provided written informed consent.

\section{Description of ALSPAC cohort and study sample}

The ALSPAC (www.bristol.ac.uk/alspac) is a UK birth cohort, from the geographical area of Avon in Southwest England, recruited between April 1991 and December 1992, with 15445 participants. ${ }^{18}$ Parents provided extensive information at baseline on their own health, demographics and lifestyle and have completed regular postal questionnaires about their child's health and development from birth. From age 7 years, the children attended a number of assessment clinics during which they took part in face-to-face interviews. The study website contains details of all the data that are available through a fully searchable data dictionary (www.bris.ac.uk/alspac/researchers/data-access/datadictionary/). Recruitment of our final study sample for this study $(n=1881)$ is illustrated in Fig. 1. From the original ALSPAC cohort, 9359 young people who were still contactable were invited to complete the 'Your Life Now (21+)' questionnaire, which included the HCL-32 questions. In the first letter, log-in details to complete the HCL-32 online were provided and in a follow-up letter both log-in details and a paper HCL-32 were provided.

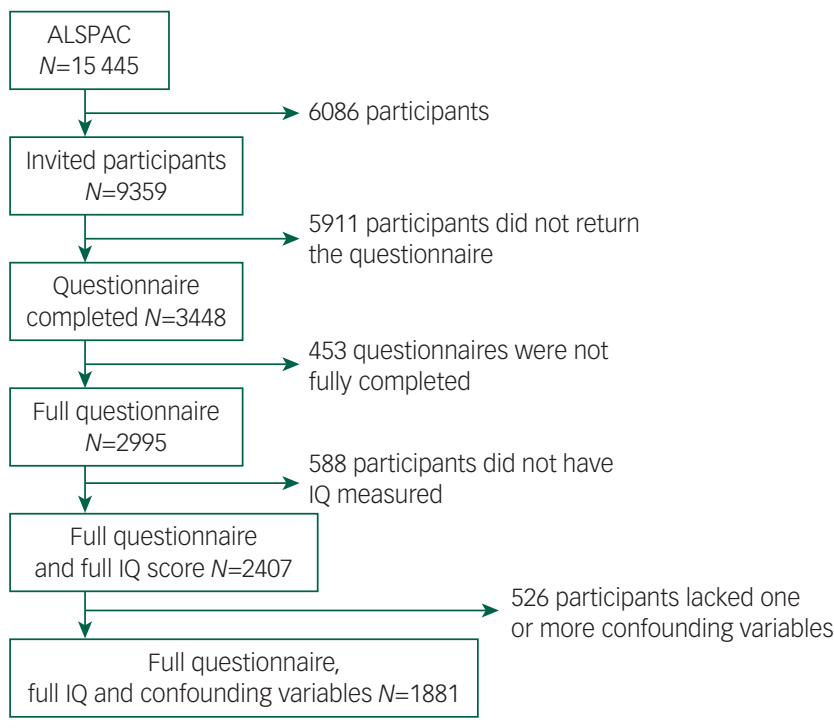

Fig. 1 Flow diagram of sample recruitment.

\section{Assessment of childhood IQ at age 8 years}

At age 8 years, the cohort was assessed on the short form of the Wechsler Intelligence Scale for Children-III (WISC-III; alternate items used for all subtests except the coding subtest), which provided a score for full-scale IQ (FSIQ), as well as scores for VIQ and PIQ. ${ }^{20}$ These scores were the primary exposure variables of interest for our study and were categorised into 'extremely low IQ' (>70), 'borderline IQ' (70-79), 'low average IQ' (80-89), 'average IQ' (90-109), 'high average IQ' (110-119), 'superior IQ' (120-129) and 'very superior IQ' (>130). We used these IQ categories (rather than raw IQ scores) because this most accurately reflects how these scores are used within educational and clinical settings, and within many previous studies of childhood IQ. This approach should make the interpretation of our findings more meaningful to clinicians.

\section{Lifetime features of bipolar disorder assessed in young adulthood}

At age 22-23 years, the cohort was invited to complete the HCL-32. ${ }^{17}$ The HCL-32 is a self-rating questionnaire that assesses lifetime history of manic symptoms. It includes detailed assessments of bipolar mood, energy and activity levels (in total 32 items). This instrument has been used extensively, validated in a number of large-scale studies, and in clinical settings is recognised to be a clinically useful screening instrument for hypomania and bipolar disorder type $\mathrm{II}^{21-26}$

We recently completed a Rasch analysis for unidimensionality of the HCL-32 manic symptoms within a sample of 389 individuals with DSM-IV bipolar disorder from the Bipolar Disorder Research Network. ${ }^{17}$ This analysis identified that four items (item 14 'I wear more colourful and more extravagant clothes/make-up'; item 29 'I drink more coffee'; item 30 'I smoke more cigarettes'; and item 32 'I take more drugs') should be eliminated to create a linear scale for lifetime bipolarity from the remaining 28 items, with raw scores converted to a score from 0 to 100 (Data supplement, Fig. DS1). ${ }^{17}$ This score for bipolarity, from here on referred to as 'lifetime manic features', is our primary outcome of interest, namely a dimensional measure of propensity to bipolar disorder assessed at age 22-23 years.

\section{Confounding variables}

Based on knowledge of social and demographic influences on IQ and previous research on the relationship between cognitive/ intellectual ability and bipolar disorder, ${ }^{10,12,14,16}$ we identified, $a$ priori, a list of childhood and maternal factors which might confound the association between childhood IQ and bipolar features in young adulthood. These factors included gender (male/female), ethnicity (White/Black and minority ethnic), handedness (left/right-handed at age 10 years), maternal social class at recruitment (I-VI), maternal age at birth (categorised as either above or below 40 years), maternal history of depression (yes/no) and maternal educational level at recruitment (educated to degree level or not). We also adjusted analyses for online versus postal completion of the HCL-32 questionnaire.

\section{Statistical analyses}

We transformed the raw 28-item manic features score into a score between 0 and 100 using the key described in our previous paper. ${ }^{18}$ A kernel density plot of the transformed score showed that it was normally distributed, so ordinary least squares were used as our modelling technique. Missing data on socioeconomic and demographic characteristics were imputed using imputation through chained equations within the 'ice' module for Stata ${ }^{27}$ and a total of 100 imputed data-sets were created. We did not impute the hypomania score. We tested for interactions with gender using 
likelihood ratio tests and compared Akaike information criterion (AIC) statistics for the regression model with VIQ and the regression model with PIQ. All analyses were carried out using Stata v13.1. ${ }^{28}$

\section{Results}

Our final study sample was made up of 1881 individuals (Fig. 1 and Table 1). The FSIQ, VIQ and PIQ scores assessed at age 8 years were normally distributed (Table 2), as were the lifetime manic features scores (Data supplement, Fig. DS2). There was evidence of differences in terms of baseline characteristics between the study sample and the wider ALSPAC cohort (Table 1). The final study sample had a greater proportion of females $(62.5 \% v$. $46.6 \%, P>0.001)$, more participants of White ethnicity $(96.9 \% v$. $94.6 \%, P>0.001)$, higher maternal social class $(P>0.001)$, higher maternal education level $(P>0.001)$ and lower rates of maternal depression $(5.0 \%$ v. 9.7\%, $P>0.001)$. They also had higher IQ assessed at age 8 years (mean FSIQ 109 (95\% CI 99-120) $v$. 102 (95\% CI 91-113), $P>0.001$; Table 2). There were no differences between the study sample and the broader ALSPAC cohort in terms of maternal age or handedness (Table 1).

\begin{tabular}{|c|c|c|c|}
\hline Characteristic & $\begin{array}{c}\text { ALSPAC } \\
\text { cohort } \\
(N=13564)\end{array}$ & $\begin{array}{l}\text { Final study } \\
\text { sample } \\
(N=1881)\end{array}$ & $P$ \\
\hline \multicolumn{4}{|l|}{ Gender, $n(\%)$} \\
\hline Females & $6044(46.6)$ & $1176(62.5)$ & 0.001 \\
\hline Males & $6933(53.4)$ & 705 (37.5) & \\
\hline Missing & $N=587$ & $N=0$ & \\
\hline \multicolumn{4}{|l|}{ Ethnicity, $n$ (\%) } \\
\hline White & $9717(94.6)$ & $1823(96.9)$ & 0.001 \\
\hline Black and minority ethnic & $555(5.4)$ & 58 (3.1) & \\
\hline Missing & $N=3292$ & $N=0$ & \\
\hline \multicolumn{4}{|l|}{ Maternal social class, $n$ (\%) } \\
\hline 1 & $424(5.1)$ & $173(9.2)$ & $0.001^{*}$ \\
\hline$\|$ & $2486(30.2)$ & 699 (37.2) & \\
\hline III & 3550 (43.1) & $778(41.4)$ & \\
\hline IV & $683(8.3)$ & $108(5.7)$ & \\
\hline V & $887(10.8)$ & $110(5.9)$ & \\
\hline $\mathrm{VI}$ & $209(2.5)$ & $13(0.7)$ & \\
\hline Armed forces & $4(0.1)$ & 0 & \\
\hline Missing & $N=5321$ & $N=0$ & \\
\hline \multicolumn{4}{|l|}{ Maternal age, $n$ (\%) } \\
\hline Age $>40$ years & $84(0.7)$ & $12(0.6)$ & 0.804 \\
\hline Age $\leq 40$ years & 12114 (99.3) & $1869(99.4)$ & \\
\hline Missing & $N=1366$ & $N=0$ & \\
\hline \multicolumn{4}{|l|}{ Maternal education, $n$ (\%) } \\
\hline Degree or above & 1175 (11.1) & $435(23.1)$ & 0.001 \\
\hline Other qualification & $9440(88.9)$ & $1446(76.9)$ & \\
\hline Missing & $N=2949$ & $N=0$ & \\
\hline \multicolumn{4}{|l|}{$\begin{array}{l}\text { Maternal history of } \\
\text { depression, } n(\%)\end{array}$} \\
\hline Yes & $1044(9.7)$ & $94(5.0)$ & 0.001 \\
\hline No & 9681 (90.3) & $1787(95.0)$ & \\
\hline Missing & $N=2839$ & $N=0$ & \\
\hline \multicolumn{4}{|l|}{ Left-handedness (child), $n$ (\%) } \\
\hline Yes & 707 (12.6) & 208 (11.1) & 0.078 \\
\hline No & 4907 (87.4) & $1673(88.9)$ & \\
\hline Missing & $N=7950$ & $N=0$ & \\
\hline \multicolumn{4}{|l|}{ Questionnaire type, $n$ (\%) } \\
\hline Paper & 0 & $847(45.03)$ & \\
\hline Online & 0 & $1034(54.97)$ & \\
\hline $\begin{array}{l}\text { ALSPAC, Avon Longitudinal Stud } \\
{ }^{*} P \text {-value was tested by test for }\end{array}$ & $\begin{array}{l}\text { Parents and } \mathrm{Ch} \\
\mathrm{d} \text {, otherwise by }\end{array}$ & 1. & \\
\hline
\end{tabular}

\begin{tabular}{|c|c|c|c|}
\hline & $\begin{array}{l}\text { ALSPAC cohort } \\
(N=13566)\end{array}$ & $\begin{array}{l}\text { Final sample } \\
\quad(N=1881)\end{array}$ & $P$ \\
\hline \multicolumn{4}{|l|}{ FSIQ, $n$ (\%) } \\
\hline$>70$ & $126(2.3)$ & $10(0.5)$ & \multirow[t]{8}{*}{$0.001^{*}$} \\
\hline 70-79 & 345 (6.3) & $51(2.7)$ & \\
\hline $80-89$ & 759 (13.9) & 137 (7.3) & \\
\hline 90-109 & $2461(45.0)$ & $760(40.4)$ & \\
\hline 110-119 & 996 (18.2) & 437 (23.2) & \\
\hline 120-129 & 434 (7.94) & $246(13.1)$ & \\
\hline$\geq 130$ & 348 (6.36) & 240 (12.8) & \\
\hline Missing & $N=8095$ & $N=0$ & \\
\hline \multicolumn{4}{|l|}{ VIQ, $n(\%)$} \\
\hline$>69$ & $88(1.6)$ & $10(0.5)$ & \multirow[t]{8}{*}{$0.001^{*}$} \\
\hline 70-79 & 227 (4.1) & $25(1.3)$ & \\
\hline $80-89$ & 621 (11.3) & $121(6.4)$ & \\
\hline 90-109 & 2515 (45.7) & 707 (37.6) & \\
\hline 110-119 & 879 (15.98) & 378 (20.1) & \\
\hline 120-129 & 735 (13.4) & 369 (19.6) & \\
\hline$\geq 130$ & 435 (7.9) & $271(14.4)$ & \\
\hline Missing & $N=8064$ & $N=0$ & \\
\hline \multicolumn{4}{|l|}{ PIQ, $n$ (\%) } \\
\hline$>69$ & 247 (4.5) & $28(1.5)$ & \multirow[t]{8}{*}{$0.001 *$} \\
\hline 70-79 & $516(9.4)$ & $98(5.2)$ & \\
\hline $80-89$ & 875 (15.9) & $216(11.5)$ & \\
\hline 90-109 & 2452 (44.7) & 831 (44.2) & \\
\hline 110-119 & 831 (15.1) & 365 (19.5) & \\
\hline $120-129$ & 334 (6.1) & $186(9.9)$ & \\
\hline$\geq 130$ & 237 (4.3) & 157 (8.4) & \\
\hline Missing & $N=8072$ & $N=0$ & \\
\hline \multirow[t]{2}{*}{ Mean FIQ (IQR) } & & & \multirow[t]{3}{*}{0.001} \\
\hline & 102 (91-113) & 109 (99-120) & \\
\hline Missing & $N=8095$ & $N=0$ & \\
\hline \multirow[t]{2}{*}{ Mean VIQ (IQR) } & & & \multirow[t]{3}{*}{0.001} \\
\hline & 104 (95-117) & $111(101-123)$ & \\
\hline Missing & $N=8064$ & $N=0$ & \\
\hline \multirow[t]{2}{*}{ Mean PIQ (IQR) } & & & \multirow[t]{3}{*}{0.001} \\
\hline & 97 (86-110) & $104(92-116)$ & \\
\hline Missing & $N=8072$ & $N=0$ & \\
\hline $\begin{array}{l}\text { ALSPAC, Avon Lon } \\
\text { verbal IQ; PIQ, perf } \\
{ }^{*} P \text {-value was teste } \\
\text { unpaired } t \text {-test. }\end{array}$ & $\begin{array}{l}\text { tudy of Parents an } \\
; \text { IQR, interquartile } \\
\text { for trend, otherwis }\end{array}$ & $\begin{array}{l}\text { Idren; FSIQ, full-s } \\
\text { Pearson's chi-squ }\end{array}$ & $\begin{array}{l}\text { IQ; VIQ, } \\
\text { test or }\end{array}$ \\
\hline
\end{tabular}

\section{Relationship between childhood IQ and lifetime manic features in young adulthood}

We found a positive association between FSIQ at age 8 years and lifetime manic features at age 22-23 years (Pearson's correlation coefficient 0.159 (95\% CI $0.120-0.198$ ), $P>0.001$ ). Individuals in the lowest decile of manic features had a mean FSIQ which was almost 10 points lower than those in the highest decile of manic features: mean FSIQ 100.71 (95\% CI 98.74-102.6) $v$. 110.14 (95\% CI 107.79-112.50), P>0.001 (Table 3). Mean VIQ and mean PIQ scores were also significantly lower within the lowest decile of manic features compared with the highest decile $(P>0.001$; Table 3$)$.

The association between IQ and manic features was present for FSIQ, VIQ and PIQ but was strongest for VIQ (Fig. 2). The 'extremely low' VIQ group (VIQ >70) scored on average 7.1 points less on the manic features scale than the normal range VIQ group (VIQ >90-109) $(P=0.044)$ and the 'very superior' VIQ group (VIQ $\geq 130$ ) scored on average 1.83 points higher on manic features than the normal VIQ group $(P=0.043)$. 
Table 3 Mean IQ scores by lowest and highest deciles of manic features scores

\begin{tabular}{|c|c|c|c|c|c|}
\hline & \multicolumn{2}{|c|}{ Lowest deciles of manic features } & \multicolumn{2}{|c|}{ Highest deciles of manic features } & \multirow[b]{2}{*}{$P$} \\
\hline & Mean & $95 \% \mathrm{Cl}$ & Mean & $95 \% \mathrm{Cl}$ & \\
\hline Full-scale IQ & 100.71 & (98.74-102.68) & 110.14 & (107.79-112.50) & $>0.001$ \\
\hline Verbal IQ & 4.27 & $(4.11-4.43)$ & 4.96 & $(4.77-5.15)$ & $>0.001$ \\
\hline Performance IQ & 3.95 & $(3.79-4.11)$ & 4.49 & $(4.30-4.68)$ & $>0.001$ \\
\hline
\end{tabular}
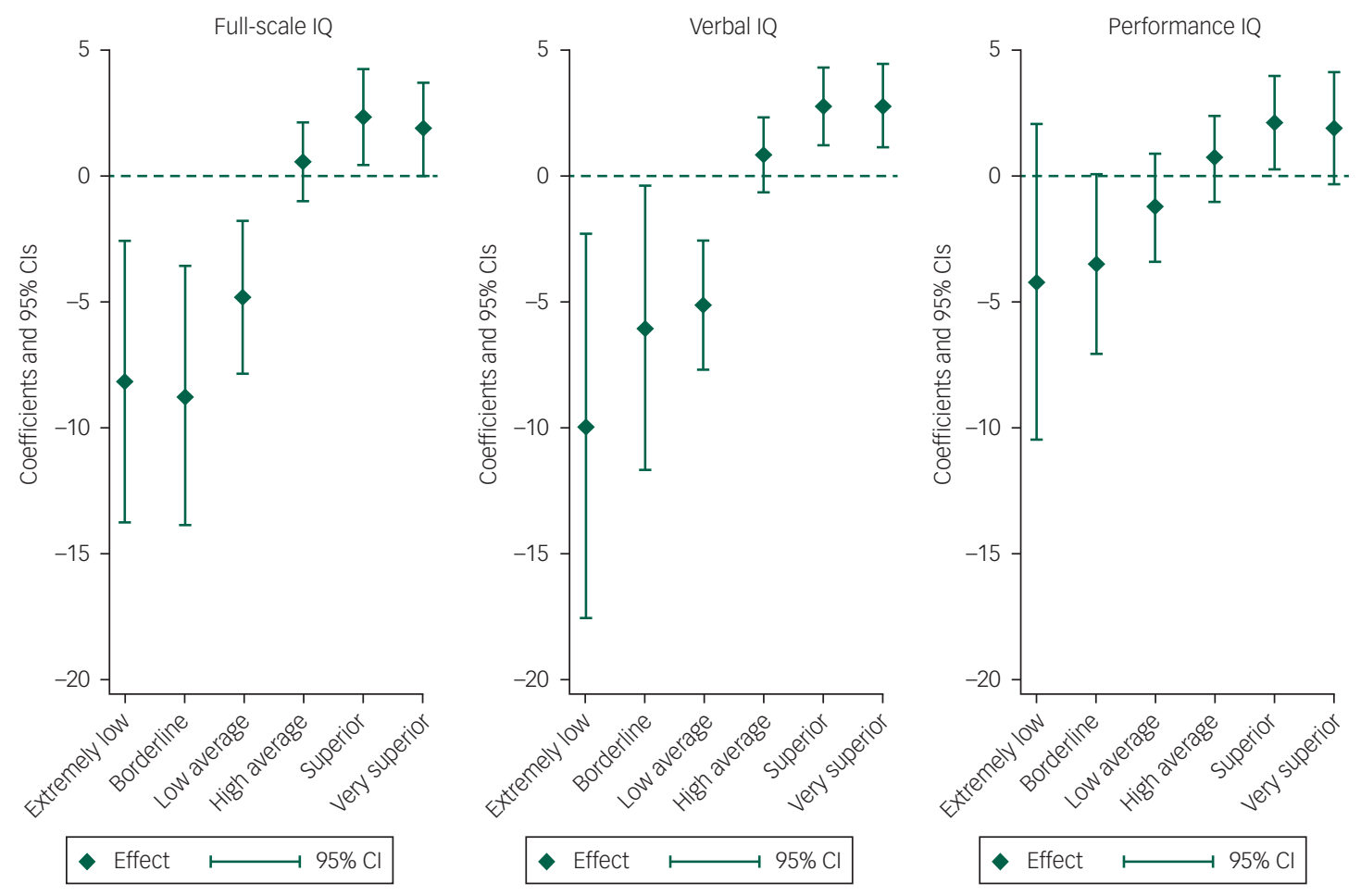

Fig. 2 Lifetime manic features score coefficients, by $1 Q$ type. ${ }^{a}$

a. Regression coefficients shown are from the multiple imputation model.

Compared with children with IQ scores in the average range (90-109), as IQ increased, from 'high average IQ', 'superior IQ' and 'very superior IQ', so the mean score for lifetime manic features increased. Similarly, as IQ decreased, from 'low average IQ', 'borderline IQ' to 'extremely low IQ', the mean score for lifetime manic features decreased. As detailed within Table 4, this was true for both unadjusted analyses and analyses which adjusted for gender, ethnicity, maternal social class, maternal age $>40$ years, maternal education, maternal history of depression, child lefthandedness and version of questionnaire. Although there was no clear evidence that the observed trends for the categorised VIQ and PIQ variables were different from each other $(P=0.11)$, the AIC statistic for the regression model with VIQ was 15160.9, compared with 15194.3 for the regression model with PIQ, suggesting that VIQ was a better predictor of lifetime manic features than PIQ. There was evidence that the relationship between VIQ and lifetime manic features was non-linear (likelihood ratio test for a quadratic relationship $P=0.002)$ but no evidence of a non-linear effect for PIQ ( $P=0.340$; Fig. 2$)$. Table 5 demonstrates that these findings were also consistent for imputed data analyses. Furthermore, on tests of interaction, there was no evidence that effects were different for males and females.

\section{Discussion}

In this large birth cohort we found that better performance on IQ tests at age 8 years, across the IQ range, was predictive of higher scores on a dimensional measure of lifetime manic features assessed in young adulthood. This association persisted after adjusting for a range of child and maternal confounding factors and there was some evidence that the association was strongest for childhood VIQ score. It is therefore possible that childhood IQ, particularly VIQ, may represent a marker of risk for prodromal or early stage bipolar disorder, although formal diagnostic assessments and longer periods of follow-up will be required to clarify this.

\section{Findings in the context of previous work}

These findings are consistent with the recent twin study by Higier and colleagues ${ }^{12}$ which found that supra-normal levels of verbal proficiency might represent a trait marker for bipolar disorder and they are in line with the work by Gale and colleagues ${ }^{16}$ who suggested that high intelligence may be a risk factor for 'pure' or 'non-comorbid' bipolar disorder in men. Although MacCabe and colleagues ${ }^{14}$ looked at the association between educational attainment (rather than IQ) and later risk of bipolar disorder, they 


\begin{tabular}{|c|c|c|c|c|}
\hline & \multicolumn{2}{|c|}{ Unadjusted ( $N=2407)$} & \multicolumn{2}{|c|}{ Adjusted $(N=1881)^{\mathrm{a}}$} \\
\hline & Regression coefficient $(95 \% \mathrm{Cl})$ & $P$ & Regression coefficient $(95 \% \mathrm{Cl})$ & $P$ \\
\hline \multicolumn{5}{|l|}{ FSIQ } \\
\hline$>70$ & $-7.00(-11.47$ to -2.53$)$ & 0.002 & $-6.87(-12.42$ to -1.32$)$ & 0.015 \\
\hline 70-79 & $-8.23(-12.70$ to -3.76$)$ & 0.001 & $-8.75(-13.87$ to -3.64$)$ & 0.001 \\
\hline 80-89 & $-3.72(-6.21$ to -1.23$)$ & 0.003 & $-4.84(-7.87$ to -1.80$)$ & 0.002 \\
\hline 90-109 & Referent group & & & \\
\hline 110-119 & $0.43(-0.97$ to 1.83$)$ & 0.548 & 0.55 (-1.04 to 2.13$)$ & 0.498 \\
\hline $120-129$ & 2.89 (1.18 to 4.60$)$ & 0.001 & 2.34 (0.46 to 4.24$)$ & 0.015 \\
\hline$\geq 130$ & 2.89 (1.32 to 4.46$)$ & 0.001 & $1.86(-0.02$ to 3.75$)$ & 0.053 \\
\hline \multicolumn{5}{|l|}{$\mathrm{VIQ}$} \\
\hline$>70$ & $-9.94(-17.53$ to -2.35$)$ & 0.010 & $-2.77(-10.43$ to 4.88$)$ & 0.478 \\
\hline 70-79 & $-6.08(-11.71$ to -0.41$)$ & 0.035 & $-11.66(-18.72$ to -4.60$)$ & 0.001 \\
\hline 80-89 & $-5.18(-7.75$ to -2.60$)$ & 0.001 & $-5.22(-8.37$ to -2.07$)$ & 0.001 \\
\hline 90-109 & Referent group & & & \\
\hline 110-119 & 0.85 (-0.62 to 2.32$)$ & 0.259 & 0.84 (-0.82 to 2.50$)$ & 0.320 \\
\hline $120-129$ & $2.76(1.23$ to 4.29$)$ & 0.001 & 2.56 (0.80 to 4.32$)$ & 0.004 \\
\hline$\geq 130$ & 2.78 (1.16 to 4.40$)$ & 0.001 & $1.91(-0.03$ to 3.85$)$ & 0.053 \\
\hline \multicolumn{5}{|l|}{ PIQ } \\
\hline$>70$ & -3.44 (-8.39 to 1.51$)$ & 0.173 & $-4.45(-10.37$ to 1.47$)$ & 0.141 \\
\hline 70-79 & $-3.00(-6.14$ to 0.14$)$ & 0.062 & $-3.40(-6.96$ to 0.16$)$ & 0.061 \\
\hline $80-89$ & $-0.75(-2.65$ to 1.16$)$ & 0.441 & $-1.26(-3.38$ to 0.86$)$ & 0.245 \\
\hline 90-109 & Referent group & & & \\
\hline 110-119 & $1.00(-0.50$ to 2.50$)$ & 0.193 & $0.67(-1.02$ to 2.36$)$ & 0.437 \\
\hline $120-129$ & 2.56 (0.87 to 4.26$)$ & 0.003 & 2.12 (0.26 to 3.99$)$ & 0.026 \\
\hline$\geq 130$ & 2.96 (0.97 to 4.94$)$ & 0.004 & $1.87(-0.36$ to 4.10$)$ & 0.100 \\
\hline
\end{tabular}

FSIQ, full-scale IQ; VIQ, verbal IQ; PIQ, performance IQ.

a Adjusted for gender, ethnicity, maternal social class, maternal age $>40$, maternal education, maternal history of depression, child left-handedness and version of questionnaire.

\begin{tabular}{|c|c|c|c|c|c|c|}
\hline \multirow[t]{2}{*}{ IQ category } & \multicolumn{2}{|l|}{ Full-scale IQ } & \multicolumn{2}{|l|}{ Verbal IQ } & \multicolumn{2}{|l|}{ Performance IQ } \\
\hline & Regression coefficient $(95 \% \mathrm{Cl})$ & $P$ & Regression coefficient $(95 \% \mathrm{Cl})$ & $P$ & Regression coefficient $(95 \% \mathrm{Cl})$ & $P$ \\
\hline$>69$ & $-7.00(-11.79$ to -2.19$)$ & 0.004 & $-9.43(-17.34$ to -1.51$)$ & 0.020 & $-3.80(-8.74$ to 1.14$)$ & 0.132 \\
\hline 70-79 & $-8.01(-12.50$ to -3.52$)$ & 0.001 & $-5.85(-11.54$ to -0.16$)$ & 0.044 & $-2.72(-5.91$ to 0.48$)$ & 0.095 \\
\hline $80-89$ & $-3.59(-6.07$ to -1.11$)$ & 0.005 & $-4.93(-7.53$ to -2.33$)$ & 0.001 & $-0.57(-2.45$ to 1.31$)$ & 0.552 \\
\hline $90-109$ & Referent group & & & & & \\
\hline $110-119$ & $0.15(-1.27$ to 1.57$)$ & 0.837 & $0.61(-0.89$ to 2.11$)$ & 0.423 & 0.82 (-0.68 to 2.33$)$ & 0.285 \\
\hline $120-129$ & $2.31(0.56$ to 4.07$)$ & 0.010 & $2.33(0.76$ to 3.91$)$ & 0.004 & $2.07(0.36$ to 3.77$)$ & 0.018 \\
\hline$\geq 130$ & 1.87 (0.19 to 3.56$)$ & 0.029 & $1.77(-0.003$ to 3.54$)$ & 0.050 & $2.00(-0.02$ to 4.02$)$ & 0.052 \\
\hline
\end{tabular}

found a positive association for men (but not for women). It is notable that, as with Higier and colleagues' twin study, we found that the association between IQ and later features of bipolar disorder applied to both men and women. We did not find that lower childhood IQ predicted manic features in adulthood.

More broadly, our finding that higher IQ scores (particularly VIQ) measured in childhood were associated with higher scores on a dimensional measure of lifetime manic features assessed in early adulthood is also consistent with research suggesting that the genetic propensity to bipolar disorder may be associated with a range of creative abilities, especially in areas where verbal proficiency may prove advantageous to the individual, such as in literature or in leadership roles. ${ }^{2,5,29}$ To some extent, this is supported by studies which have identified that the clinical states of mania and hypomania are associated with both greater combinatory thought processes $^{30}$ and greater associational fluency. ${ }^{3-33}$

Most neurocognitive research on bipolar disorder has found that individuals, as well as to a lesser extent their non-bipolar first-degree relatives, have subtle deficits in verbal memory, sustained attention and executive function ${ }^{34-36}$ and that these impairments are associated with functional impairment. ${ }^{37,38}$ These deficits may also get worse over time with repeated episodes of illness. ${ }^{39,40}$ In this regard, it could be considered surprising that we did not find an association between lower childhood IQ and manic features in young adulthood. However, the neurodevelopmental trajectory of bipolar disorder (in contrast to schizophrenia) is not characterised by significant motor delays and cognitive difficulties in childhood, with many individuals who later go on to develop bipolar disorder performing at least as well as the general population ${ }^{41}$ (although bipolar disorder with an onset in childhood may have a neurodevelopmental profile which is closer to that of schizophrenia). ${ }^{42}$ It is therefore possible that our findings refer to a group of young adults in the early or prodromal stages of bipolar disorder, a proportion of whom may not ultimately go on to develop the full-blown disorder. 


\section{Strengths and limitations}

The study analysed data from a large birth cohort that is representative of the UK general population in terms of ethnicity, social class and educational attainment. The assessment of childhood IQ at age 8 years, approximately 14 years before the assessment of manic features, as well as the depth of baseline data that were available for assessing the impact of confounding factors, all represent major methodological strengths.

Our primary outcome of interest was a dimensional score for lifetime manic features, derived from 28 items selected from the HCL-32 questionnaire. ${ }^{18}$ Clearly, as noted above, higher scores on this instrument are not diagnostic of bipolar disorder but we would argue that higher transformed scores on this measure are a good quantitative assessment of propensity to bipolar disorder, particularly in a population sample of young adults who are likely to be still below the age threshold for experiencing a first episode of mania. ${ }^{43,44}$ The use of dimensional measures of psychopathology in this way is consistent with a view of mental disorders as quantitative traits. ${ }^{45}$ Furthermore, the dimensional nature of the modified questionnaire fits with prior research supporting a dimensional nature of vulnerability to mania. ${ }^{46}$ This is also in line with recent recommendations that dimensional, rather than strict categorical approaches, such as those suggested within the Research Domain Criteria, ${ }^{47,48}$ may be more useful for understanding the aetiology of psychiatric conditions. ${ }^{49}$ There is now good evidence that lifetime features of mania occur along a spectrum of mood and psychotic disorders that includes (but is likely not limited to) the categorical diagnoses of recurrent major depressive disorder, bipolar disorder and schizophrenia. $^{50-54}$

Possible limitations of the HCL-32 instrument include the fact that, as a self-report measure, it may be subject to reporting biases, for example, in areas such as sexual activity, risk taking and alcohol use, where young adults might be more likely to respond affirmatively to these statements. However, this instrument has been used very widely in young adult populations and is well validated with respect to screening for bipolar disorder in clinical and young adult population settings. ${ }^{22}$ The opening statement specifically asks respondents to remember 'a period when you were in a high state, not related to recreational drug use.' It is still possible that scores on this questionnaire may have been related to current drug or alcohol use but unfortunately we did not have a contemporaneous measure which would allow us to take this into account within our analyses. Further, it is unlikely that drug or alcohol use would have confounded the IQ measures because they were taken at age 8 years.

Another important limitation relates to the extent to which our study sample is representative of the original ALSPAC cohort and, more broadly, the general population. It is likely that there was an attrition bias in this study. Compared with the rest of the ALSPAC cohort, our study sample had higher IQ, higher maternal social class, higher maternal education level and lower rates of maternal depression. There was also a greater proportion of females and participants of White ethnicity. This attrition represents a limitation of this study but to minimise this possibility we used multiple imputation (Table 5). Within these imputed analyses our findings were similar to the complete case analyses.

\section{Implications}

In evolutionary terms, our findings suggest that there may be some selective advantage associated with propensity to serious recurrent disorders of mood such as bipolar disorder. Higher IQ in childhood is likely to advantageous for the long-term reproductive fitness of our species but it is possible that the trade-off for this is greater liability to recurrent depression and/or bipolar disorder. Our findings open the way for more detailed genetic investigations of the relationship between intelligence and bipolar disorder (including, for example, polygenic risk score approaches), as well as assessments of the extent to which childhood IQ might represent an endophenotypic marker for later bipolar disorder. Future work should also assess the contribution of copy number variations (CNVs) to this relationship between IQ and bipolar disorder, given that large CNVs are more strongly associated with schizophrenia, autism and intellectual disability than with bipolar disorder. ${ }^{55}$ Finally, our findings support quite recent evidence that VIQ or verbal proficiency may represent biomarkers or endophenotypes for bipolar disorder ${ }^{12}$ and in this regard should stimulate future work on the genetic relationship between VIQ and recurrent disorders of mood such as bipolar disorder.

In summary, this prospective study has identified that performance on childhood IQ tests at age 8 years was positively correlated across the IQ range with lifetime features of bipolar disorder experienced in early adulthood, even after adjusting for a range of confounding factors. Clinically, these findings may have implications for the development of approaches which seek to identify subgroups of adolescents and young adults who may be at higher risk of developing bipolar disorder, for example, those with exceptional verbal proficiency in the context of other known risk factors for bipolar disorder, such as high genetic loading, ${ }^{56}$ exposure in utero to influenza ${ }^{57}$ or childhood trauma. ${ }^{58}$

Daniel J. Smith, MD, Institute of Health and Wellbeing, University of Glasgow, Glasgow, Scotland, UK; Jana Anderson, PhD, Institute of Health and Wellbeing, University of Glasgow, Glasgow, Scotland, UK; Stanley Zammit, PhD, Institute of Psychological Medicine and Clinical Neurosciences, Cardiff University School of Medicine, Cardiff, Wales, UK; Thomas D. Meyer, PhD, Department of Psychiatry \& Behavioral Sciences, University of Texas Medical School at Houston, Houston, TX, USA; Jill P. Pell, MD, Institute of Health and Wellbeing, University of Glasgow, Glasgow, Scotland, UK: Daniel Mackay, PhD, Institute of Health and Wellbeing, University of Glasgow, Glasgow, Scotland, UK

Correspondence: Daniel J. Smith, Institute of Health and Wellbeing, University of Glasgow, 1 Lilybank Gardens, Glasgow, Scotland G12 8RZ, UK. Email: daniel.smith@ glasgow.ac.uk

First received 2 Mar 2015, final revision 6 May 2015, accepted 26 Jun 2015

\section{Funding}

This research was funded by a Strategic Start-up Grant to DJS from the University of Glasgow.

\section{Acknowledgements}

We thank all families who took part in this study, the midwives for their help in recruiting them, and the whole ALSPAC team, which includes interviewers, computer and laboratory technicians, clerical workers, research scientists, volunteers, managers, receptionists and nurses. The UK Medical Research Council and the Wellcome Trust (Grant ref: 102215/2/13/2) and the University of Bristol provide core support for ALSPAC. This publication is the work of the authors and DJS will serve as guarantor for the contents of this paper.

\section{References}

1 Haldane J. Manic Depression and Creativity. Prometheus Books, 1998.

2 Richards R, Kinney DK, Lunde I, Benet M, Merzel AP. Creativity in manicdepressives, cyclothymes, their normal relatives, and control subjects. I Abnorm Psychol 1988; 97: 281-8.

3 Duke P. A Brilliant Madness: Living With Manic-Depressive Illness. Bantam Dell Pub Group, 1992

4 Jamison KR. Touched with Fire: Manic Depressive Illness and the Artistic Temperament. Free Press, 1993. 
5 Murray G, Johnson SL. The clinical significance of creativity in bipolar disorder. Clin Psychol Rev 2010; 30: 721-32.

6 Andreasen NC. Creativity and mental illness: prevalence rates in writers and their first-degree relatives. Am J Psychiatry 1987; 144: 1288-92.

7 Jamison KR. Mood disorders and patterns of creativity in British writers and artists. Psychiatry 1989; 52: 125-34.

8 Post F. Creativity and psychopathology. A study of 291 world-famous men. $\mathrm{Br}$ J Psychiatry 1994; 165: 22-34.

9 Ludwig AM. Mental illness and creative activity in female writers. Am J Psychiatry 1994; 151: 1650-6.

10 Kyaga S, Lichtenstein P, Boman M, Hultman C, Långström N, Landén M. Creativity and mental disorder: family study of 300000 people with severe mental disorder. Br J Psychiatry 2011; 199: 373-9.

11 Kyaga S, Lichtenstein $\mathrm{P}$, Boman M, Landén M. Bipolar disorder and leadership - a total population study. Acta Psychiatr Scand 2014; 131: 111-9.

12 Higier RG, Jimenez AM, Hultman CM, Borg J, Roman C, Kizling I, et al. Enhanced neurocognitive functioning and positive temperament in twins discordant for bipolar disorder. Am J Psychiatry 2014; 171: 1191-8.

13 Koenen KC, Moffitt TE, Roberts AL, Martin LT, Kubzansky L, Harrington HL, et al. Childhood IQ and adult mental disorders: a test of the cognitive reserve hypothesis. Am J Psychiatry 2009; 166: 50-7.

14 MacCabe JH, Lambe MP, Cnattingius S, Sham PC, David AS, Reichenberg A, et al. Excellent school performance at age 16 and risk of adult bipolar disorder: national cohort study. Br J Psychiatry 2010; 196: 109-15.

15 Zammit S, Allebeck P, David AS, Dalman C, Hemmingsson T, Lundberg I, et al. A longitudinal study of premorbid IQ score and risk of developing schizophrenia, bipolar disorder, severe depression, and other nonaffective psychoses. Arch Gen Psychiatry 2004; 61: 354-60.

16 Gale CR, Batty GD, McIntosh AM, Porteous DJ, Deary IJ, Rasmussen F. Is bipola disorder more common in highly intelligent people? A cohort study of a million men. Mol Psychiatry 2013; 18: 190-4.

17 Angst J, Adolfsson R, Benazzi F, Gamma A, Hantouche E, Meyer TD, et al. The HCL-32: towards a self-assessment tool for hypomanic symptoms in outpatients. J Affect Disord 2005; 88: 217-33.

18 Court H, Forty L, Jones L, Gordon-Smith K, Jones I, Craddock N, et al. Improving the psychometric utility of the Hypomania checklist (HCL-32): a Rasch analysis approach. J Affect Disord 2014; 152-154: 448-53.

19 Boyd A, Golding J, Macleod J, Lawlor DA, Fraser A, Henderson J, et al. Cohort profile: the 'children of the 90s'-the index offspring of the Avon Longitudinal Study of Parents and Children. Int J Epidemiol 2012; 42: 111-27.

20 Wechsler D. The Wechsler Intelligence Scale for Children-Third Edition. The Psychological Corporation, 1991.

21 Meyer TD, Hammelstein P, Nilsson LG, Skeppar P, Adolfsson R, Angst J. The Hypomania checklist (HCL-32): its factorial structure and association to indices of impairment in German and Swedish nonclinical samples. Compr Psychiatry 2007; 48: 79-87.

22 Meyer TD, Schrader J, Ridley M, Lex C. The Hypomania checklist (HCL) systematic review of its properties to screen for bipolar disorders. Compr Psychiatry 2014; 55: 1310-21.

23 Angst J, Azorin JM, Bowden CL, Perugi G, Vieta E, Gamma A, et al. Prevalence and characteristics of undiagnosed bipolar disorders in patients with a major depressive episode: the BRIDGE study. Arch Gen Psychiatry 2011; 68: 791-9.

24 Forty L, Smith D, Jones L, Jones I, Caesar S, Fraser C, et al. Identifying hypomanic features in major depressive disorder using the hypomania checklist (HCL-32). J Affect Disord 2009: 114: 68-73.

25 Smith DJ, Griffiths E, Kelly M, Hood K, Craddock N, Simpson SA. Unrecognised bipolar disorder in primary care patients with depression. Br J Psychiatry 2011; 199: 49-56.

26 Carta MG, Hardoy MC, Cadeddu M, Murru A, Campus A, Morosini PL, et al. The accuracy of the Italian version of the Hypomania Checklist (HCL-32) for the screening of bipolar disorders and comparison with the Mood Disorder Questionnaire (MDQ) in a clinical sample. Clin Pract Epidemiol Ment Health 2006; 2: 2

27 Royston P. Multiple imputation of missing values. Stata J 2004; 4: 227-41.

28 StataCorp. Stata Statistical Software: Release 13.2013. StataCorp LP.

29 Santosa CM, Strong CM, Nowakowska C, Wang PW, Rennicke CM, Ketter TA Enhanced creativity in bipolar disorder patients: a controlled study. J Affect Disord 2007; 100: 31-9.

30 Solovay MR, Shenton ME, Holzman PS. Comparative studies of thought disorders: I. Mania and schizophrenia. Arch Gen Psychiatry 1987; 44: 13-20.

31 Henry GM, Weingartner $\mathrm{H}$, Murphy DL. Idiosyncratic patterns of learning and word association during mania. Am J Psychiatry 1971; 128: 564-74.
32 Pons L, Nurnberger Jr Jl, Murphy DL. Mood-independent aberrancies in associative patterns in bipolar disorder: an apparent stabilizing effect of lithium. Psychiatry Res 1985; 14: 315-22

33 Levine J, Schild K, Kimhi R, Schreiber G, Word associative production in affective versus schizophrenia psychoses. Psychopathology 1996; 29: 7-13.

34 Bourne C, Aydemir Ö, Balanzá-Martínez V, Bora E, Brissos S, Cavanagh JT, et al. Neuropsychological testing of cognitive impairment in euthymic bipolar disorder: an individual patient data meta-analysis. Acta Psychiatr Scand 2013; 128: 149-62

35 Glahn DC, Almasy L, Barguil M, Hare E, Peralta JM, Kent Jr JW, et al. Neurocognitive endophenotypes for bipolar disorder identified in multiplex multigenerational families. Arch Gen Psychiatry 2010; 67: 168-77.

36 Bora $E$, Yucel M, Pantelis C. Cognitive endophenotypes of bipolar disorder: a meta-analysis of neuropsychological deficits in euthymic patients and their firstdegree relatives. J Affect Disord 2009; 113: 1-20.

37 Malhi G, Ivanovski $B$, Hadzi-Pavlovic D, Mitchell PB, Vieta E, Sachdev $P$. Neuropsychological deficits and functional impairment in bipolar depression, hypomania and euthymia. Bipolar Disord 2007; 9: 114-125

38 Torres IJ, DeFreitas CM, DeFreitas VG, Bond DJ, Kunz M, Honer WG, et al. Relationship between cognitive functioning and 6-month clinical and functional outcome in patients with first manic episode bipolar I disorder. Psychol Med 2011; 41: $971-82$.

39 Gildengers AG, Mulsant BH, Begley A, Mazumdar S, Hyams AV, Reynolds lii CF, et al. The longitudinal course of cognition in older adults with bipolar disorder Bipolar Disord 2009; 11: 744-52.

40 Moorhead TWJ, McKirdy J, Sussmann JE, Hall J, Lawrie SM, Johnstone EC, et al. Progressive gray matter loss in patients with bipolar disorder. Biol Psychiatry 2007; 62: 894-900.

41 Demjaha $\mathrm{A}$, MacCabe $\mathrm{JH}$, Murray RM. How genes and environmental factors determine the different neurodevelopmental trajectories of schizophrenia and bipolar disorder. Schizophr Bull 2012; 38: 209-14.

42 Arango C, Fraguas D, Parellada M. Differential neurodevelopmental trajectories in patients with early-onset bipolar and schizophrenia disorders. Schizophr Bull 2014; 40 (Suppl 2): S138-46

43 Leboyer M, Henry C, Paillere-Martinot ML, Bellivier F. Age at onset in bipolar affective disorders: a review. Bipolar Disord 2005; 7: 111-8.

44 Hamshere ML, Gordon-Smith K, Forty L, Jones L, Caesar S, Fraser C, et al. Age-atonset in bipolar-I disorder: mixture analysis of 1369 cases identifies three distinct clinical sub-groups. J Affect Disord 2009; 116: 23-9.

45 Plomin R, Haworth CM, Davis OS. Common disorders are quantitative traits. Nat Rev Genet 2009; 10: 872-8.

46 Meyer TD, Keller F. Is there evidence for a latent class called "hypomanic temperament"? J Affect Disord 2003; 75: 259-67.

47 Cuthbert B, Insel TR. Toward the future of psychiatric diagnosis: the seven pillars of RDOC. BMC Med 2013; 11: 126.

48 Insel TR, Cuthbert B, Garvey $\mathrm{M}$, Heinssen R, Pine DS, Quinn, K, et al. Research domain criteria (RDOC): toward a new classification framework for research on mental disorders. Am J Psychiatry 2010; 167: 748-51.

49 Insel TR. The NIMH research domain criteria (RDOC) project: precision medicine for psychiatry. Am J Psychiatry 2014; 171: 395-7.

50 Cardno AG, Owen MJ. Genetic relationships between schizophrenia, bipolar disorder, and schizoaffective disorder. Schizophr Bull 2014; 40: 504-15.

51 Cassano GB, Rucci P, Frank E, Fagiolini A, Dell'Osso L, Shear KM, et al. The mood spectrum in unipolar and bipolar disorder: arguments for a unitary approach. Am J Psychiatry 2004; 161: 1264-9.

52 Wiste A, Robinson EB, Milaneschi Y, Meier S, Ripke S, Clements CC, et al. Bipolar polygenic loading and bipolar spectrum features in major depressive disorder. Bipolar Disord 2014; 16: 608-16.

53 Angst J. The bipolar spectrum. Br J Psychiatry 2007; 190: 189-91.

54 Craddock N, Owen MJ. The beginning of the end for the Kraepelinian dichotomy. Br J Psychiatry 2005; 186: 364-6.

55 Green EK, Rees E, Walters JT, Smith KG, Forty L, Grozeva D, et al. Copy number variation in bipolar disorder. Mol Psychiatry 2015; 6 Jan, doi: 10.1038/mp.2014.174.

56 Craddock N, Sklar P. Genetics of bipolar disorder. Lancet 2013; 381: 1654-62.

57 Canetta SE, Bao YY, Co MDT, Ennis FA, Cruz J, Terajima M, et al. Serological documentation of maternal influenza exposure and bipolar disorder in adult offspring. Am J Psychiatry 2014; 171: 557-63.

58 Etain B, Aas M, Andreassen OA, Lorentzen S, Dieset I, Gard S, et al. Childhood trauma is associated with severe clinical characteristics of bipolar disorders. I Clin Psychiatry 2013; 74: 991-8. 